\title{
Interpreting the American Midwest: A Review Essay
}

\author{
TOM MORAIN
}

The American Midwest: An Interpretive Encyclopedia, edited by Richard Sisson, Christian Zacher, and Andrew Cayton. Bloomington: Indiana University Press, 2007. xxiv, 1,891 pp. Illustrations, index. $\$ 75.00$ cloth.

TO SAY that The American Midwest: An Interpretive Encyclopedia is an ambitious work is like saying that Bill Gates's income is in the " $\$ 75,000$ or above" bracket. Both statements are true, but neither prepares you for the shock that accompanies the revelation of details. This tome of 1,891 pages weighs in at nearly nine pounds. It taps the wisdom of hundreds of academic scholars from the Midwest and beyond in a collective self-study of a subject that, from the outset, even the editors confess they cannot define precisely.

The preface credits John Gallman, former director of Indiana University Press, as the instigator of the project. He proposed the collaboration to Richard Sisson, a former interim president of Ohio State University and then professor of comparative politics, and Christian Zacher, director of Ohio State's Institution for Collaborative Research and Public Humanities. Both were well connected to scholarly networks and knew how to attract institutional support. They then recruited Andrew Cayton, professor of history at Miami University, and the three-Sisson, Zacher, and Cayton-assumed the roles of general editors.

Cayton's "General Overview" articulates the questions that guided the work's development. Is the Midwest a "distinctive

THE ANNALS OF IOWA 66 (Winter 2007). (C) The State Historical Society of Iowa, 2006. 
place"? Are there sufficient unifying threads in the expanse between the Appalachians and the Great Plains to warrant discussing it as a coherent region? That question is hardly rhetorical in view of the area's extensive geographical scope. The focus includes 12 states - Ohio, Indiana, Illinois, Wisconsin, Michigan, Minnesota, Iowa, Nebraska, Kansas, Missouri, North and South Dakota. It is indeed a long way by car and by culture from southeastern Ohio to western North Dakota and from the Little Egypt region of southern Illinois to Minnesota's Iron Range.

For the editors, process is as important as product. "The guiding principle of this work is a belief that the process of contemplating that question is as important as any answers offered individually or collectively by our authors" (xix). Ingenuous as that approach is - publication vindicates the effort-it is not a scholastic slam-dunk. Is the Midwest a "distinctive place"? Distinctive to whom? Midwesterners? Or those who define the United States as "two coasts connected by United Airlines"?

One place to start is to pose the question to a group of bright, articulate, socially conscious, civic-minded midwesterners themselves, that is, readers of the Annals of Iowa. Gentle Reader, how do you respond to the question of midwestern regional identity? What does it mean to you? How often and in what contexts do you think of yourself as a midwesterner? If asked where they live, most Iowans would probably answer in one of three ways, depending on who is asking the question. To another Iowan, we would identify ourselves by our home town. To an American outside of Iowa, we would respond, "Iowa." To a foreigner, "an American." Hometown, state, nation. We skip over township, county - and region. I can think of no occasion when I have asked someone who they are or where they live and the response has been, "I' $\mathrm{m}$ a midwesterner." That is not, of course, a definitive answer to the question of midwestern regional identity. It does suggest, however, that perspectives that tie us together as "midwesterners," regardless of how well scholars can document them, may be secondary factors in how we perceive ourselves.

Come at the question from a different perspective. Think of the unique Iowa traditions, events, and cultural icons that we identify as "ours" or characteristics of "where I come from." 
Here are some items on my list: the state fair, high school basketball tournaments, RAGBRAI, the state capitol and Old Capitol, Grant Wood, the presidential caucuses, the state's reputation for quality education, the Iowa-Iowa State athletic rivalry. Now, try to think of a similar list that you share with other midwesterners. The Big Ten athletic conference comes to mind. The team names locate it solidly in the Midwest-Ohio State, Indiana, Illinois, Wisconsin, Michigan, Michigan State, Minnesota, Iowa (and also Purdue and Northwestern). But what else? What unites me with citizens of North Dakota, Kansas, and Ohio that makes me think of them as "us"? Of cultural symbols as "ours"? For me it is a short list.

However, a success of The American Midwest is that the list grows the more one reads it. The editors themselves have no doubts about the historical, economic, and political significance of the region. To Iowans who so often hear our state described in terms of what it lacks - no mountains, forests, seacoasts, or megacities-Cayton's characterization of midwestern history will sound hauntingly familiar. Historians have paid less attention to the region, he claims, because its history is "largely a narrative of the accumulation of ordinary events into large-scale change rather than a story of dramatic turning points" (xix). Translated: It's not very exciting. However, he quickly adds, the sum total of those "ordinary events" has been enormous.

The conquest, settlement, and development of what we call the Midwest is one of the most important events in the past quarter millennium of human history. ... No other place ... better reflects the combined impact of the democratic revolutions of the eighteenth century and the transportation, communication, and industrial revolutions of the nineteenth century. No other place on earth brought so many different human beings together in such a short period of time to negotiate and fashion new ways of life. No other place better exemplifies the values of market capitalism as well as ideals of social equality, civic culture, and local democracy (xix).

I agree.

With the completed manuscript in hand, editor Cayton assessed the contributors' responses to two questions. First, "Is the Midwest simply a microcosm of the United States?" (xxiii). Not surprisingly, the scholars' subject matter often pre-ordains 
their response. Some found nothing distinctly midwestern in their subjects, Cayton summarizes, "thereby reinforcing the common wisdom that the Midwest is the least recognizable (or interesting) of American regions" (xxiii). Others put a unique midwestern spin on the major developments that have occurred in America's heartland. In the samples that I read, however, most scholars spend more time describing local institutions located in the Midwest and much less time comparing them individually or collectively to those of other regions. It is difficult to get a sense of distinctiveness unless one is already familiar with another region.

The second question is almost rhetorical: "Is the Midwest a region of unbroken sameness?" (xxiii). Geography alone dictates a negative answer to that one. University of Kansas geographer James R. Shortridge explores the subject of regional identity from a historical vantage point and explains that the image of the Midwest as homogeneous is a recent creation, originating only after World War II. He then examines three themes that have dominated the national perception of the region: "the vastness, fertility, and climatic extremes of the land; the pastoral nature of the society; and the blend there of youthful vigor and mature judgment" (58).

THE OPENING SECTION of The American Midwest begins with a "portrait" of each of the 12 states, "consciously idiosyncratic essays about the particular qualities of the various states" (xxiii). The late Kurt Vonnegut penned the work on his home state of Indiana, and folklorist Roger Welsch lovingly contrasts the divide between Nebraska's eastern prairies and its western plains. Iowa's chronicle comes from Susan Allen Toth, an author of several autobiographical works on her Iowa roots. She creates a very introspective and subjective essay about her love for the Iowa landscape. It mingles elements of a travelogue with a list of famous Iowans, some of whose ties with the state, she notes, were short lived. Personally, I found it long on imagery and short on substance, but not for lack of Toth's deep affection for her subject. Trying to make the case that the Iowa generally perceived to be so bland and predictable is actually full of surprises, she writes: "Once anyone looks hard at Iowa, it begins to 
shimmer with possibilities, rather like the enigmatic cornfields in Field of Dreams" (15). Unfortunately, the same cannot be said for her essay.

The remainder of the encyclopedia is divided into five sections: Landscapes and People; Society and Culture; Community and Social Life; Economy and Technology; and Public Life. Each section is then divided into subsections that are further divided into specific topics. The overviews by distinguished scholar/editors are excellent. The approach works better for some topics than for others, at least in the comprehensiveness of the final product. For example, under "Society and Culture" are subsections on "Language," "Folklore," and eight others. "Language" is further divided into essays on "Varieties of English" and then "Native American Languages," "European Languages," and additional languages spoken in the region. It is highly probable that one could come to the encyclopedia seeking information on a particular language and find a good source of material.

The "Folklore" subsection is more of a problem, not surprisingly given the nature of the topic. A "Folklore" table of contents lists topics one would expect to find, such as "Crafts," "Folklore," and "Song," but the supporting topics are decidedly eclectic. The four essays under "Foodways" include catfish, church dinners, lutefisk, and wild rice. Trying to do a general survey of church dinners in 1,000 words or less is a tough assignment. However, after each essay, a note on sources and suggestions for further reading point the reader to additional sources, a great boon to those seeking in-depth information.

An insight that may surprise many readers appears in Jon Gjerde's introduction to the "Peoples" subsection. He asserts that a factor mitigating against a regional identify for midwesterners is the pervasive cultural diversity itself. Gjerde does not bother to refute the stereotype that depicts a population of bland homogeneity. Instead, he boldly posits the opposite: "One of the most distinguishing characteristics of the region is its ethnic and racial heterogeneity" (179). What follow are essays on 45 different ethnic groups, including Woodlands and Plains Indians and métis from the eighteenth century and the recently arrived Asian Indians, Filipinos, and Lebanese, each with its 
own bibliography for further reading. This section could become a valuable first stop for genealogists, historians, and students alike. (With so many possibilities, it may be petty to pick out one that is missing, but in the current political climate, I found the omission of Detroit's Arab population unfortunate.)

It is probably safe to predict that few readers will begin at the start of the "Peoples" section and read through each essay. Most will seek out information on a particular group and then perhaps browse a minute or two through nearby articles. That is unfortunate. Reading the entire section, comparing and contrasting the experiences of various groups, might very well provide new insights into the current debate on immigration policy and other issues. The people of the Midwest are immigrants or children of immigrants. Some have more of a memory than others.

AS A BORN-AND-BRED IOWA BOOSTER, I naturally had my radar up for references to things Iowa. I was pleased to see John T. Frederick and the Midland magazine mentioned in the "Literature" section along with, of course, the Iowa Writers Workshop. There are essays on Carrie Chapman Catt and George Horace Gallup and his roots in Jefferson, Iowa. There was even mention of Ames native Peter Schickele, whose explorations on the musical innovations of P.D.Q. Bach have delighted classical music audiences.

With its conception in Indiana and Ohio, the encyclopedia probably is guilty of weighting coverage of the eastern Midwest over the western states. Nevertheless, Iowa is well represented. Annals of Iowa readers will spot many familiar names. Frank Yoder contributes essays on the role of ethnicity and kinship in rural life and on the role of class in farm neighborhoods. Doug Hurt, Tim Mahoney, and Peverill Squire all served as senior consulting editors. Former University of Iowa president Mary Sue Coleman, now president of the University of Michigan, was on the national editorial advisory board. And, lest we overlook the obvious, Grant Wood's The Birthplace of Herbert Hoover graces the front of the dust jacket.

On one point I must express my frustration, not with editorial content but with gravity. The volume is big and it is heavy. 
Unfortunately, the sheer massive bulk of the book and the nature of its essays work against each other. With many other large reference books, size is not a problem. You know the information you want. You pull the book down from the shelf, take it to a library table, and look up what you need. Although The American Midwest is an amazing source of information, it is not essentially a facts book or an almanac. It is, according to its subtitle, An Interpretive Encyclopedia. You may go to it for one topic, but interpretive essays lend themselves to browsing. So often in preparing this review, I would start in one section and then spot something that looked interesting in a different section and start reading there. But a nine-pound book does not lend itself to browsing. This is not a coffee-table book. It needs a library table, and a sturdy one at that. It is not comfortable to hold it in your lap in an armchair. If you prop it up on your knees in bed, you could face domestic assault charges if it falls off and strikes your spouse. I understand the economics of printing. It would be too expensive to print in multiple volumes. Nevertheless, I fear that the size of the book will limit the productive serendipity that comes to readers who spend time browsing through its voluminous content. Likewise, at $\$ 75$, The American Midwest will not find its way into many home libraries.

That is too bad because the collection is a wonderful resource. Will its readers come to it because they are anxious to decide if the American Midwest is a distinct cultural region? Probably not. But if they come to it enough times, they may begin to discover new threads they had never considered that do unite the peoples of this ethnically and racially heterogeneous region. Furthermore, the weight training will do them good. 